\title{
Effects of short-term variation in food availability on larval development in the barnacle Balanus amphitrite amphitrite
}

\author{
Jian-Wen Qiu*, Louis A. Gosselin**, Pei-Yuan Qian \\ Department of Biology, The Hong Kong University of Science and Technology Clear Water Bay, Kowloon, Hong Kong
}

\begin{abstract}
The effects of short-term variation in food availability on larval survival and development of the barnacle Balanus amphitrite amphitrite Darwin were studied in the laboratory. We found that 0.5 and $1 \mathrm{~d}$ intervals of alternating feeding and starvation did not influence survivorship of stage II nauplii, but lengthened the duration of development by about $40 \%$; survivorship of nauplius JI initially starved for 2 and $3 \mathrm{~d}$ was $>25 \%$ lower than in the continuously fed controls, and larval development was prolonged by $>1.5 \mathrm{~d}$. Four-day initial starvation in nauplius II led to $100 \%$ larval mortality. Initial starvation also significantly affected feeding time required to complete nauplius II. Although initial starvation in nauplius II affected larval survival and duration of development, those larvae reaching cypris stage all metamorphosed into juveniles. The minimum feeding time required for completion of nauplius II was extended by $>8 \mathrm{~h}$ for each day of initial starvation, for up to $2 \mathrm{~d}$ initial starvation. Feeding time required to complete individual naupliar stages also increased with larval development. Continuous access to food beyond the minimum feeding time shortened the duration of development. Our data suggest that $B$. amphitrite amphitrite larvae can survive short-term starvation and that such ability may help them overcome a patchy food supply in the field. However, sublethal starvation will lengthen the duration of development, thus increasing exposure to sources of mortality such as predation or misrouting. Since initial starvation in the nauplius II stage did not influence the metamorphic capacity of cyprids in the laboratory, sublethal starvation during larval development should not affect bioassay results.
\end{abstract}

KEY WORDS: Barnacle - Balanus - Larval development - Starvation - Larvae

\section{INTRODUCTION}

In coastal habitats, spatial and temporal variations in the concentration of suspended food particles, such as phytoplankton (Mackas et al. 1985, Pitcher et al. 1991, Franks 1992, Litaker et al. 1993), can lead to considerable differences in feeding opportunities for planktotrophic invertebrate larvae. To assess the significance of such variations for larval performance, numerous studies have examined the relationship between food concentration and survivorship and growth by rearing larvae at different food concentrations in the laboratory. Larvae developing at low food concen-

\footnotetext{
·E-mail: bojwqiu@uxmail.ust.hk

- Present address: Department of Biology, University College of the Cariboo, Kamloops, British Columbia, Canada V2C 5N3
}

trations were found to have lower growth rates, longer development times, smaller sizes at competence, more extensive feeding structures, or reduced survivorship relative to individuals developing at higher food concentrations (Hartnoll 1982, Pechenik 1987, Strathmann 1987. Olson \& Olson 1989, Qian \& Chia 1991, 1993, Strathmann et al. 1992, Fenaux et al. 1994).

A dimension of food availability which has received much less attention is variation in food availability within the larval period of the individual. In the field, individuals are likely to encounter varying levels of food availability during the larval phase rather than constant food concentrations. Rapid changes in the availability of planktonic food sources can occur as a result of interactions between suspended food particles and parameters of the water column (e.g. pelagic grazers, chemical and physical properties of the water column) 
(Mackas et al. 1985, Young \& Chia 1987), localized depletion by benthic filter-feeders (Butman et al. 1994), the displacement of patch fronts (Franks 1992), and via vertical migrations of larvae (Young \& Chia 1987).

In the present study, we used Balanus amphitrite amphitrite Darwin (Ren \& Liu 1978, Foster 1982), a barnacle species common in tropical and subtropical coastal waters, to examine the the implications of short-term food limitation for larval development. Specifically, we determined (1) whether larvae require continuous access to food to successfully complete larval development, (2) the tolerance of larvae to initial periods of starvation (i.e. at the stage when feeding would normally begin), (3) the effects of initial starvation periods on subsequent feeding requirements and intermolt period, and (4) whether development rate is influenced by food availability after the larva has acquired the minimum needed to molt to the next nauplius stage. The results of this study will help us understand how periodic food limitation influences larval development rate and the survival of barnacle larvae and how important it is for larvae to remain within paiches of high food concentration.

\section{MATERIAL AND METHODS}

Study organism and general methods. The larval development of Balanus amphitrite amphitrite consists of 6 naupliar stages and 1 cypris stage (Hudinaga \& Kasahara 1941, Costlow \& Bookhout 1958, Wu \& Cai 1963). The non-feeding nauplius I molts to nauplius II within 2 to 4 h of spawning. Larval development ceases at nauplius II under low food or starvation conditions (Qiu \& Qian 1997). However, if sufficient food is provided (e.g. $\geq 10^{4}$ cells $\mathrm{ml}^{-1}$ of Skeletonema costatum), nauplius II can continue to develop to nauplius VI and then molt to the cyprid stage, which is non-feeding and competent to settle. Standard procedures have been established to use the cypris larvae of this species to evaluate the performance of various antifouling methods (Mary et al. 1987). These larvae do not grow on bacteria (Gosselin \& Qian 1997) and are therefore largely dependent on phytoplankton or other organic particles as food sources

The procedures for collecting and maintaining $\mathrm{Bal}$ anus amphitrite amphitrite broodstock have been described by Qiu \& Qian (1997). Briefly, adult barnacles $(>100)$ placed in 2 separate buckets were induced to spawn by changing the water and exposing them to intense light. Nauplius I larvae from both buckets were collected and mixed together. All nauplius I larvae molted to nauplius II within $3 \mathrm{~h}$. Newly molted nauplius II were attracted to a point-source of light and collected using a pipette.
Four experiments described herein were conducted from December 1995 to May 1997. The chain-forming diatom Skeletonema costatum, cultured in a modified f/2 medium (Guillard 1975), was used as food, at a concentration of $1 \times 10^{5}$ cells $\mathrm{ml}^{-1}$ In the non-feeding regimes, larvae were placed in $0.22 \mu \mathrm{m}$ filtered seawater $\left(32 \%\right.$ salinity). Crystamycin $\left(22.5 \mathrm{mg} \mathrm{l}^{-1}\right.$ penicillin $\mathrm{G}$ and $37.5 \mathrm{mg} \mathrm{\textrm {l } ^ { - 1 }}$ streptomycin sulfate) was added to the larval cultures to inhibit bacterial growth. Previous studies indicated that the addition of the above antibiotics at the indicated concentrations in larval culture had no adverse effect on barnacle larval development (Tighe-Ford et al. 1970). Larval cultures were maintained at $20^{\circ} \mathrm{C}$ under a $12 \mathrm{~h}$ light $/ 12 \mathrm{~h}$ dark photoperiod, except in Expt 1, where cultures were maintained at $28^{\circ} \mathrm{C}$.

Expt 1: effects of intermittent food availability. To determine how the development of Balanus amphitrite amphitrite larvae is affected by short-term discontinuity in food availability, newly molted nauplius II were exposed to alternating feeding and non-feeding periods of 0.5 or $1 \mathrm{~d}$ duration (Fig. 1). For the 0.5 and $1 \mathrm{~d}$ treatments, nauplius II larvae were initially placed in dishes containing $10 \mathrm{ml}$ of Skeletonema costatum suspension. After each 0.5 or $1 \mathrm{~d}$ interval, larvae were transferred between $S$. costatum and filtered seawater in an alternating sequence. For the continuous feeding treatment (control), newly molted nauplius II larvae were exposed to $S$. costatum throughout the experiment, with daily change of culture media. In total, 90 nauplius II were used ( 3 treatments $\times 3$ replicates $\times 10$ larvae). Each dish was checked for molts and dead larvae twice a day, until all larvae had either developed into cyprids or died.

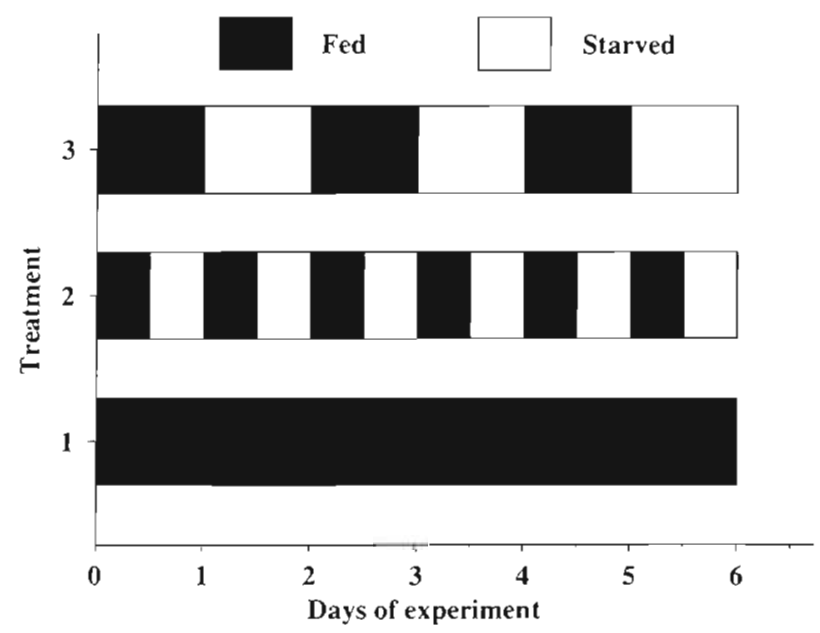

Fig. 1. Balanus amphitrite amphitrite. Design for Expt 1. Horizontal bars represent the duration of larval development for the 3 treatments: continuous food supply, alternating feeding or starving for 0.5 or $1 \mathrm{~d}$ 
Expt 2: tolerance to initial starvation. To determine the ability of Balanus amphitrite amphitrite larvae to recover from initial periods of starvation, newly molted nauplius II larvae were starved for periods of 0.5 to $4 \mathrm{~d}$ and were then provided with food (Table 1). For the control, newly molted nauplius II larvae were transferred into dishes containing $10 \mathrm{ml}$ of Skeletonema costatum suspension immediately after molting from nauplius I. For the 5 starvation treatments, newly molted nauplius II were starved in filtered seawater $(0.22 \mu \mathrm{m})$ for $0.5,1,2,3$, and $4 \mathrm{~d}$, respectively, before being transferred into $S$. costatum suspensions. In total, 180 nauplius II larvae $(6$ treatments $\times 3$ replicates $\times 10$ larvae) were used. The culture medium was changed daily. During each change, dishes were checked for molts and dead larvae, until all nauplius II had either developed into cyprids or died. The ability to complete the transition from competent larvae to early juvenile was determined for cyprids from each treatment by placing cyprids individually in polystyrene Petri dishes containing $15 \mathrm{ml}$ seawater and $S$. costatum at a concentration of $10^{4}$ cells $\mathrm{ml}^{-1}$, until they either died or attached and metamorphosed. To prevent cyprids from being trapped at the air-water surface, Petri dishes were filled with well-aerated water and sealed. Individuals were checked daily until all cyprids had either metamorphosed or died.

Expt 3: Minimum Feeding Time (MFT) at different naupliar stages and effects of initial starvation on the MFT of nauplius II. Expts 1 \& 2 revealed that barnacle nauplii do not need to feed continuously in order to obtain enough energy and nutrients to molt to the next stage, indicating that larvae may not feed for all of the intermolt period. The shortest feeding duration sufficient to ensure successful molting is defined as Minimum Feeding Time (MFT). To determine the MFT of Balanus amphitrite amphitrite larvae, we used newly molted nauplius II, III, and V (to test whether MFT changes during development) and nauplius II starved for 1 and $2 \mathrm{~d}$ (to test whether MFT is affected by initial starvation). These larvae were allowed to feed on Skeletonema costatum for different periods of time before being transferred into filtered seawater (Table 1). To test whether MFT of nauplius II is affected by initial starvation, newly molted nauplius II, and nauplius II starved for 1 and $2 \mathrm{~d}$ in $0.22 \mu \mathrm{m}$ filtered seawater (32\%) were each divided into 6 groups of 10 larvae (each group with 3 replicates, total larvae: 3 starvation treatments $\times 6$ feeding time treatments $\times 10$ larvae $\times$ 3 replicates $=540$ larvae) and placed in dishes containing $10 \mathrm{ml}$ of $S$. costatum suspension. Nauplius II starved for 0 to $2 \mathrm{~d}$ were allowed to feed for either 0 (control), 2, 4, 8, 12, or $24 \mathrm{~h}$, before being transferred into filtered seawater. Nauplius III and $\mathrm{V}$ were obtained by feeding a batch culture of stage II nauplii with $S$. costatum. Before a desired stage was reached, larvae were removed from the stock culture and placed individually into dishes containing filtered seawater. This ensured that larvae had enough reserves to molt to the next stage but had no algae to feed after molting. Larvae at a desired stage were collected for the experiments as soon as they molted. Newly molted nauplius III and $V$ were each divided into 6 groups of 10 larvae, each group with 3 replicates (total larvae: 2 stages $\times 6$ feeding time treatments $\times 10$ larvae $\times 3$ replicates $=360$ larvae), and placed in dishes containing $10 \mathrm{ml} \mathrm{ml}$ of $S$. costatum suspension. Larvae at different developmental stages were allowed to feed for either 0 (control), 2, 4, 8, 12, or $24 \mathrm{~h}$, before being transferred into filtered seawater. Dishes were checked daily for molts and dead larvae until all nauplii had either developed into the next stage (nauplius II $\rightarrow$ III, nauplius III $\rightarrow$ IV, nauplius $V \rightarrow$ VI) or died.

Expt 4: effects of food availability beyond MFT on development rate. The results of Expt 3 indicated that the time needed to obtain enough food to develop to

Table 1. Balanus amphitrite amphitrite. Design for Expts 2 to 4

\begin{tabular}{|cccc|}
\hline Expt & Stage and condition at onset & Duration of food availability & Parameters measured \\
\hline 2 & NII (starved for $0 \mathrm{~d}$ ) & Continuous & Numbers of NII reaching cyprid; \\
& NII (starved for $0.5 \mathrm{~d}$ ) & Continuous & time required for completion of the \\
& NII (starved for $1 \mathrm{~d}$ ) & Continuous & \\
& NII (starved for $2 \mathrm{~d}$ ) & Continuous & \\
& NII (starved for $3 \mathrm{~d}$ ) & Continuous & \\
& NII (starved for $4 \mathrm{~d}$ ) & Continuous & NII to cyprid \\
3 & NII (starved for $0 \mathrm{~d}$ ) & $0,2,4,8,12$ or $24 \mathrm{~h}$ & to next stage (NII $\rightarrow$ NIII, \\
& NII (starved for $1 \mathrm{~d}$ ) & $0,2,4,8,12$ or $24 \mathrm{~h}$ & NIII $\rightarrow$ NIV, NV $\rightarrow$ NVI) \\
& NII (starved for $2 \mathrm{~d}$ ) & $0,2,4,8,12$ or $24 \mathrm{~h}$ & \\
& NIII (starved for $0 \mathrm{~d}$ ) & $0,2,4,8,12$ or $24 \mathrm{~h}$ & Time required to molt to next \\
& NV (starved for $0 \mathrm{~d}$ ) & $0,2,4,8,12$ or $24 \mathrm{~h}$ & stage (NIl $\rightarrow$ NIII, NVI $\rightarrow$ cyprid) \\
\hline
\end{tabular}


the next stage was substantially shorter than the intermolt period. In Expt 4, we determined whether continued access to food beyond MFT influenced the rate of development (Table 1). Newly molted nauplius II and VI larvae were fed for either 12 h or continuously. In total, 240 nauplii ( 2 stages $\times 2$ treatments $\times 5$ replicates $\times 12$ larvae) were used. For nauplius II, larvae were either allowed to feed for $12 \mathrm{~h}$ before being transferred to filter-seawater or fed continuously. Cultures were checked at $24,30,36,42,48,60$, and $72 \mathrm{~h}$, at which time all larvae had either molted to nauplius III or died. For nauplius VI, the same food treatments were used and cultures were checked at $36,48,60,72,84$, and $96 \mathrm{~h}$ for molts and dead larvae, at which time all nauplii had either developed into cyprids or died.

Data analysis. Statistical procedures followed Zar (1984). Data were tested for normality using the Shapiro-Wilk test before proceeding with statistical analysis. When data were not nomally distributed, they were either analyzed by Friedman's test (when there were $2 \times 2$ treatments) to compare treatment effects or by ANOVA using ranked data followed by Tukey tests to compare treatment ettects. In Expt 1, 1-way ANOVA and Tukey tests were used to determine the effects of intermittent food availability on development time from nauplius II to cyprid. Data were ranked before analyses were performed. In Expt 2, the average duration of larval development and percentage of nauplius II reaching the cyprid stage were compared using 1-way ANOVA on ranked data followed by Tukey test. In Expt 3, a 1-way ANOVA using ranked data and Tukey test were used to determine the effects of time of food availability $(0,2,4,8,12,24 \mathrm{~h}$ food) on percentage of larvae molting to the next stage. A 2-way ANOVA using ranked data and a Tukey test were used to determine the effects of time of food availability and larval starvation history $(0,1,2$ d starvation), or larval stages (nauplius II, III, V) on percentage of larvae molting to the next stage. In Expt 4, Friedman's test was used to compare effects of food availability $(12 \mathrm{~h}$ vs continuous food supply) and developmental stage (nauplius II vs nauplius VI) on intermolt duration. A $t$-test was used to compare effects of food availability $(12 \mathrm{~h}$ vs continuous food supply) on intermolt duration in both nauplius II and nauplius VI.

\section{RESULTS}

\section{Expt 1: effects of intermittent food availability}

The objective of this experiment was to determine how the development of Balanus amphitrite amphitrite larvae is affected by short-term discontinuity in food

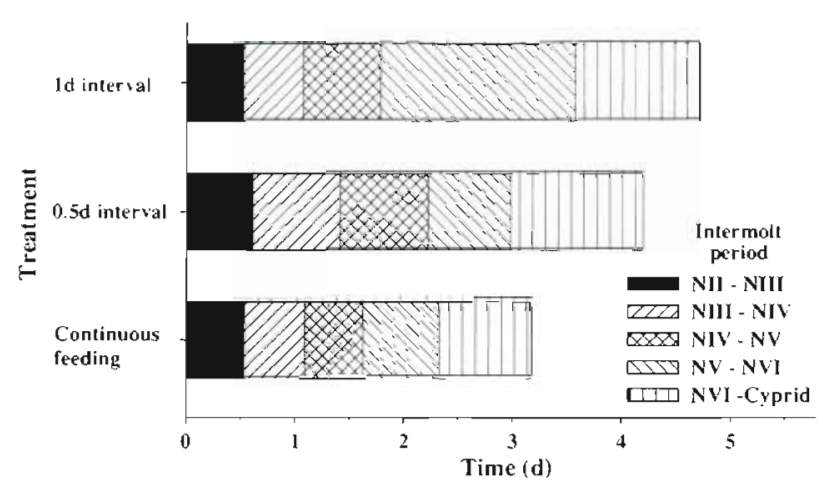

Fig. 2. Balanus amphitrite amphitrite. Effects of intermittent food availability on larval development. Data are plotted as means of 3 replicate cultures. Stacked bars represent duration of development at nauplius II to VI with the 3 food treatments (Fig. 1). The total length of each of the 3 bars represents total larval development time. Total larval development time did not differ significantly between the 2 intermittent food treatments, but it was significantly longer than in the continuous food supply treatment

availability. All 90 larvae successfully developed through to the cypris stage. Total larval development time, however, differed significantly among the 3 treatments (Fig. 2; $\mathrm{p}=0.0008, \mathrm{n}=90$ ). The 0.5 and $1 \mathrm{~d}$ intervals of alternate feeding and starving resulted in similar development times, which were slower than that of the control by 32.2 to $57.3 \%$ (mean number of days needed to reach cypris stage $\pm \mathrm{SD}: 4.19 \pm 0.18 \mathrm{~d}$ for $0.5 \mathrm{~d}, 4.70 \pm 0.40 \mathrm{~d}$ for $1 \mathrm{~d}$ intermittent food supply, and $3.16 \pm 0.02 \mathrm{~d}$ for continuous food supply).

\section{Expt 2: tolerance to initial starvation}

The objective of this experiment was to determine the ability of Balanus amphitrite amphitrite larvae to recover from initial periods of starvation. Starving nauplius II larvae for $4 \mathrm{~d}$ led to mortality of all larvae in the treatment. Shorter durations of initial starvation led to significantly more larvae reaching the cypris stage ( $\mathrm{p}<0.0001, \mathrm{n}=18$ ) and shorter larval development times $(\mathrm{p}<0.0001, \mathrm{n}=124)$ (Fig. 3). There were no significant differences among the 0 (control), 0.5 and $1 \mathrm{~d}$ initial starvation treatments in either the percentage of larvae reaching the cypris stage or time to complete larval development. Two and three days of initial starvation lowered the percentage of nauplius II completing larval development by $>25 \%$, and lengthened larval development time by $>1.5 \mathrm{~d}$ relative to the control.

Sublethal starvation during the nauplius II stage had no subsequent effect on the capacity of cyprids to metamorphose into juveniles. When observed under a dissecting microscope, all juveniles were active and 


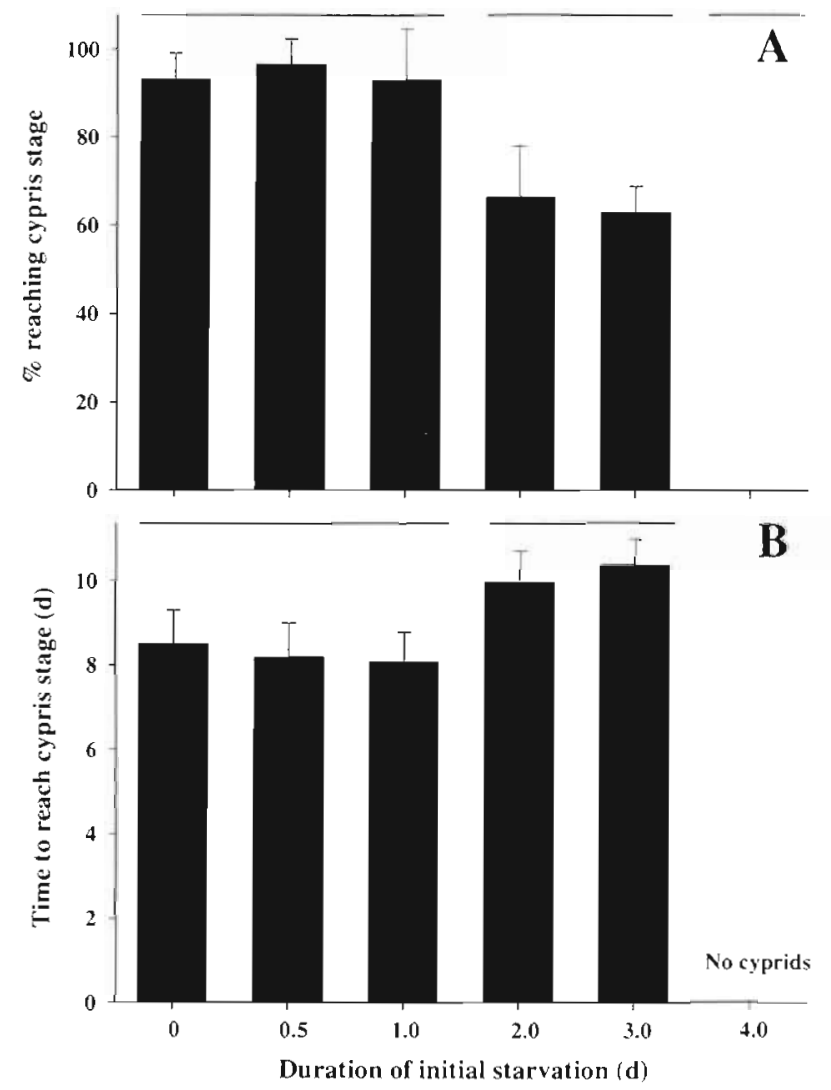

Fig. 3. Balanus amphitrite amphitrite. Effects of initial starvation on duration of larval development (measured from the time nauplius II were given access to food to the time they became cyprids; the starvation period was not included). (A) Percentage of larvae reaching cypris stage. (B) Duration of larval development. Data are plotted as mean $+\mathrm{SD}, \mathrm{n}=3$ per treatment. Values that do not differ at 0.05 level in Tukey tests, following a 1-way ANOVA using ranked data, are indicated by a line above the bars

appeared healthy. Of the 124 cyprids in the experiment, 122 successfully metamorphosed and developed into early juveniles. Only 2 cyprids, 1 in the control and another in the $1 \mathrm{~d}$ initial starvation treatment, died. The duration of the cypris stage varied considerably within starvation treatments as well as among treatments (Fig. 4). In the first 2 d, 15 to $30 \%$ of the cyprids metamorphosed, but all cyprids metamorphosed or died within $8 \mathrm{~d}$.

\section{Expt 3: MFT at different naupliar stages and effects of initial starvation on the MFT of nauplius II}

The objective of this experiment was to determine the MFT of newly molted nauplius II, III, and V (to test whether MFT changes during development) and nauplius II starved for 1 and $2 \mathrm{~d}$ (to test whether MFT is affected by initial starvation).

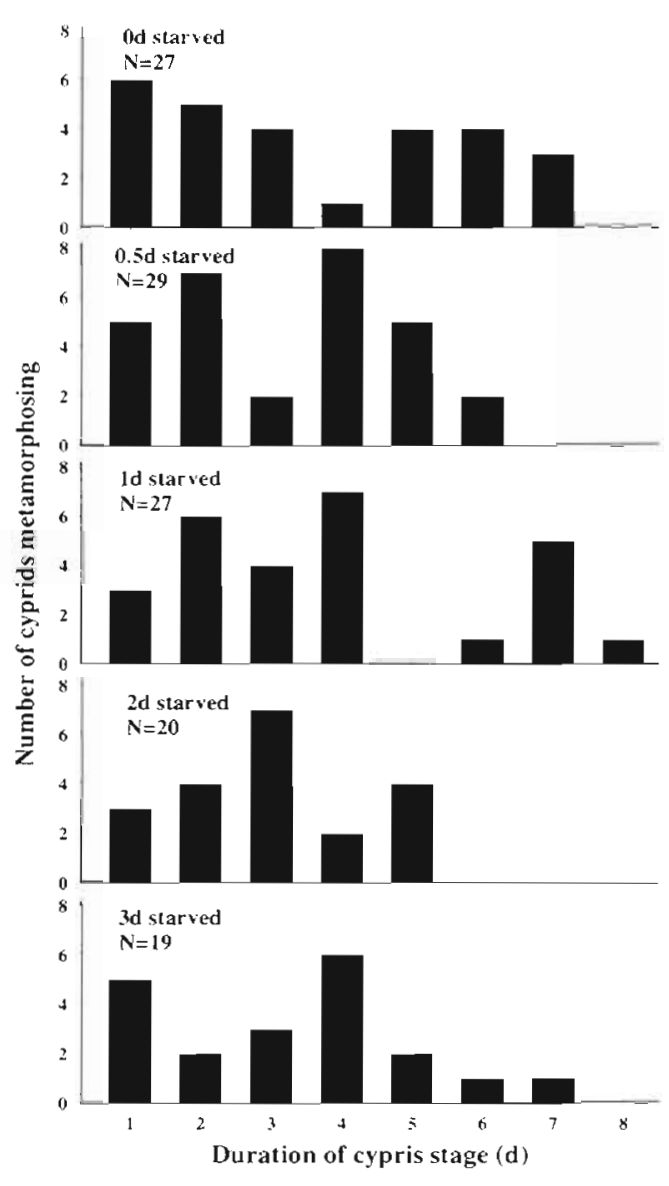

Fig. 4. Balanus amphitrite amphitrite. Effects of starvation during the nauplii ll stage on duration of the cypris stage. Data from 3 replicates were pooled. N: number of cyprids metamorphosing

In nauplius II, initial starvation for 1 and $2 \mathrm{~d}$ led to significantly different MFTs (Fig. 5A, B, C, Table 2). The duration of feeding resulting in $10 \%$ larvae molting to nauplius III (MFT 10 ) was 2,4 , and $8 \mathrm{~h}$ for newly molted, 1 d starved, and 2 d starved nauplius II, respectively. $\mathrm{MFT}_{10}$ for nauplius II to reach nauplius III was therefore doubled for each day of starvation for up to $2 \mathrm{~d}$ starvation. The duration of feeding resulting in $50 \%$ of nauplius II molting to nauplius III (MFT 50 ) was 4,12 , and 24 h for newly molted, 1 d starved, and $2 \mathrm{~d}$ starved nauplius II, respectively, accounting for 12.9 , 38.7 , and $77.4 \%$ of the intermolt duration for the continuously fed nauplius II larvae. Initial starvation periods of 1 and $2 \mathrm{~d}$ resulted in an extended $\mathrm{MFT}_{50}$ value by $\geq 8 \mathrm{~h}$ for each day of starvation.

There were significant differences in MFT among nauplius II, III, and V larvae (Fig, 5A, D, E, Table 2). $\mathrm{MFT}_{10}$ was $2 \mathrm{~h}$ for newly molted nauplius II and nauplius III, but considerably longer for nauplius $V(8 \mathrm{~h})$. $\mathrm{MFT}_{50}$ increased as larvae reached later stages (nauplius II: $4 \mathrm{~h}$, nauplius III: $8 \mathrm{~h}$, nauplius V: $12 \mathrm{~h}$ ). 


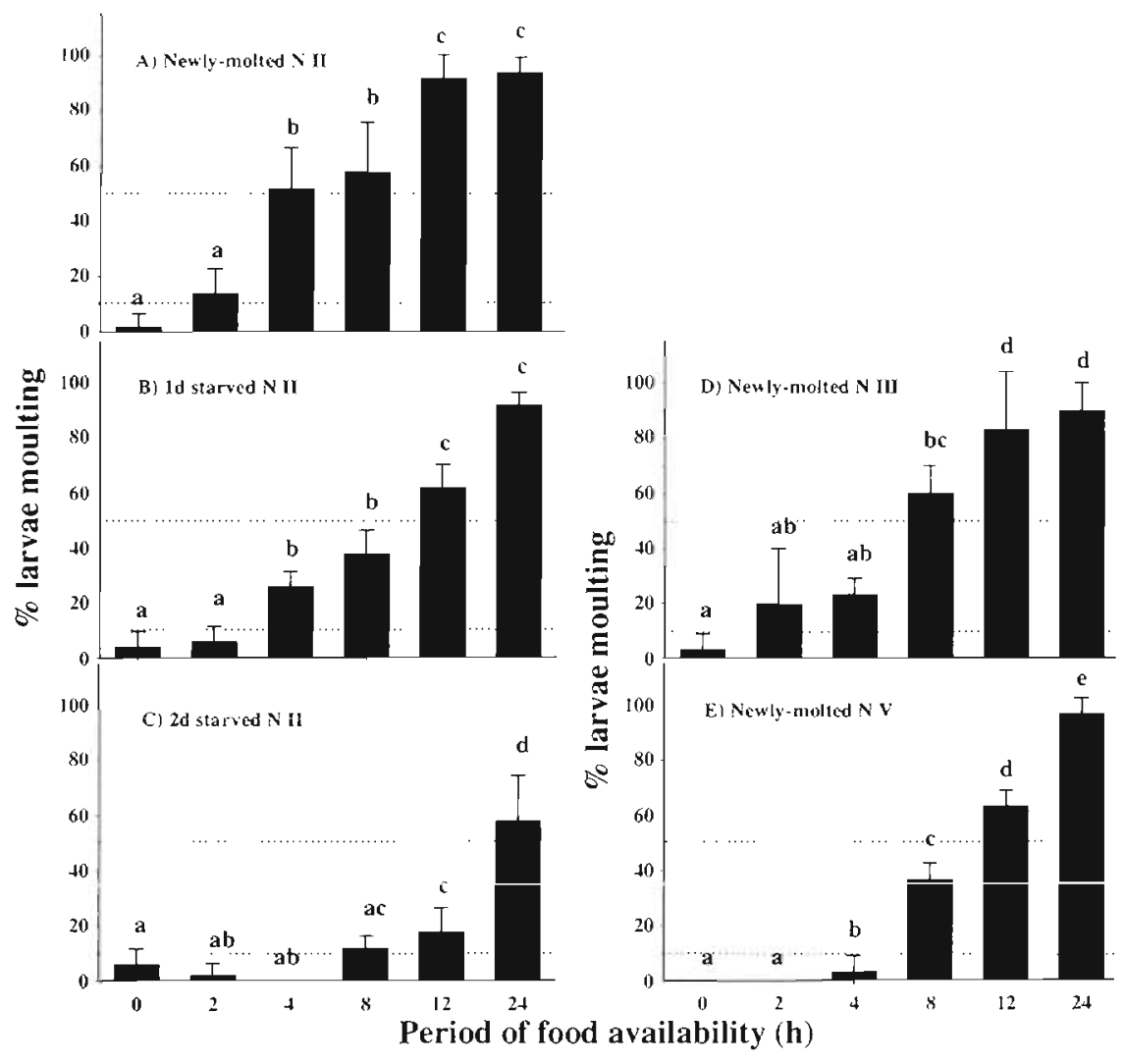

Fig. 5. Balanus amphitrite amphitrite Feeding time required to complete individual larval stages during development, and effects of initial starvation on the feeding time of nauplius II. Data are plotted as mean $+\mathrm{SD}, \mathrm{n}=3$ per treatment. Horizontal dash lines indicate 10 and $50 \%$ larvae molting to next stage. Values that do not differ at 0.05 level in Tukey tests, following a 1 -way ANOVA using ranked data, are indicated by the same letter above the bars. (A) Newly molted nauplius II; (B) $1 \mathrm{~d}$ starved nauplius $\mathrm{II}_{\text {; }}$ (C) $2 \mathrm{~d}$ starved nauplius $I_{i}$ (D) newly molted nauplius III (E) newly molted nauplius $V$

\section{Expt 4: effects of food availability beyond MFT on development rate}

The objective of this experiment was to determine whether continued access to food beyond MFT affected the rate of development. There were significant differences in intermolt duration between the 2 naupliar stages (nauplius II and VI, p $<0.0001$ ), and between the $12 \mathrm{~h}$ and continuous food availability treatments ( $\mathrm{p}<0.0001, \mathrm{n}=103$ ) (Fig. 6). When food was continuously available, the average intermolt

Table 2. Balanus amphitrite amphitrite. Expt 3. Summary of 2-way ANOVA tests of the effects of feeding time and initial starvation or feeding time and larval stage on percentage of larvae molting to the next stage. Data were ranked before ANOVA was performed

\begin{tabular}{|lrrc}
\hline Source & df & $F$ & $p$ \\
\hline \multicolumn{3}{l}{ Effects of initial starvation and feeding time } \\
Initial starvation $(0,1,2 \mathrm{~d})$ & 2 & 90.12 & 0.0001 \\
Feeding time & 5 & 128.57 & 0.0001 \\
Initial starvation $\times$ Feeding time & 10 & 9.89 & 0.0001 \\
Effects of larval stage and feeding time & & \\
Larval stage (NII, NIII, NV) & 2 & 9.81 & 0.0001 \\
Feeding time & 5 & 117.89 & 0.0001 \\
Stage $\times$ Feeding time & 10 & 2.06 & 0.0001 \\
& & & \\
\end{tabular}

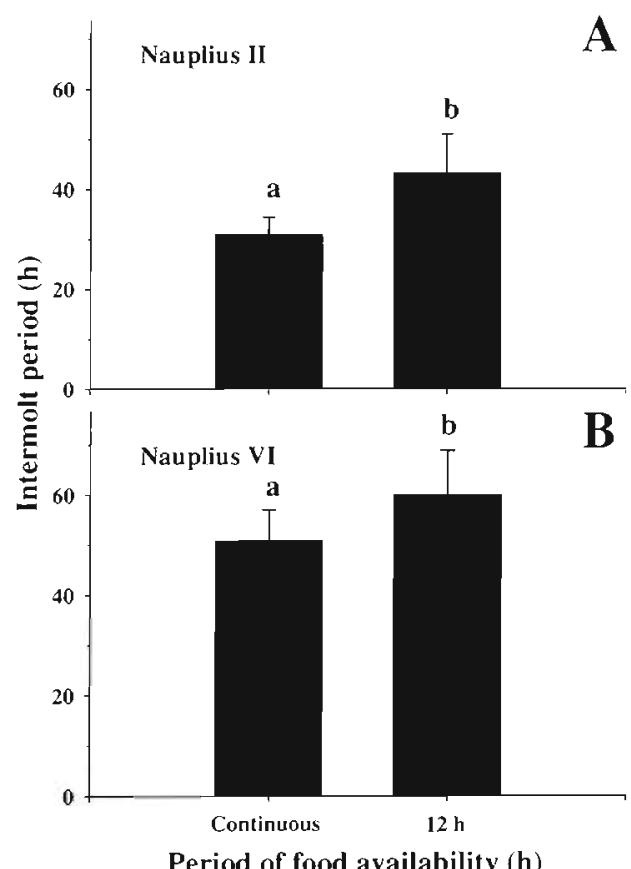

Period of food availability (h)

Fig. 6. Balanus amphitrite amphitrite. Effects of continuous food availability beyond minimum feeding time on intermolt duration. Data are plotted as mean $+\mathrm{SD}, \mathrm{n}=5$ per treatment. Values that do not differ at the 0.05 level in the $t$-test are indicated by the same letter above the bars. (A) Nauplius II; (B) nauplius VI 
duration for nauplius II was $31 \mathrm{~h}$ but considerably longer for nauplius VI $(51 \mathrm{~h})$. When food was available for only $12 \mathrm{~h}$, intermolt duration was also longer in nauplius VI (60 h) than in nauplius II (43 h) (Fig. 6).

Discontinuity in access to food significantly extended development time relative to continuous feeding treatment (Fig. 6). Intermolt duration in the continuous access to food treatment was shorter than in the $12 \mathrm{~h}$ feeding treatments by $39.33 \%$ (nauplius II) and $17.65 \%$ (nauplius VI).

\section{DISCUSSION}

Crustacean larvae are generally thought to be more sensitive to starvation than are mollusc and echinoderm larvae (see review of Olson \& Olson 1989). Among crustacean larvae, however, sensitivity to starvation differs dramatically. For example, the larval development of the crab Sesarma curacaoense is quite independent of external food sources (Anger 1995). During zoeal development, food is eaten when available, but zoeal development can be completed even in the complete absence of food. Moreover, when the preceding zoeal stages have been fed continuously, megalopae are able to complete their entire molt cycle without food (Anger 1995). Zoeal development of $S$. reticulatum, however, is more dependent on external food sources (Anger 1995), as only zoea I can molt to the next stage without food. Larval development in $S$. cinereum is even more dependent on external food, as none of the larval stages can molt to the next stage without feeding (Staton \& Sulkin 1991). These differences in resistance to starvation within 1 genus suggest that maternal investment may be very different from species to species. Thus far, the effects of partial starvation had been studied in only 1 barnacle species, Balanus improvious (Lang \& Marcy 1982). Our results show that nauplius II of $B$. amphitrite amphitrite could withstand initial periods of starvation $\leq 3 \mathrm{~d}$. This is somewhat shorter than what was found in nauplius II of $B$. improvious, where larvae could survive up to 6-7 d of starvation (Lang \& Marcy 1982). Both studies (Lang \& Marcy 1982, this study) suggest that barnacle larvae can survive short-term starvation. Such an ability may help them cope with patchy food supplies in the field.

In our study, short-term starvation influenced both survivorship and duration of development. Intermittent food supply prolonged larval development (Fig. 2), and initial starvation for 2 to $3 \mathrm{~d}$ reduced survivorship and prolonged larval development and MFT (Figs. 3 $\&$ 5). Continuous access to food reduced intermolt duration (Fig. 6). Similarly, in Balanus improvisus, nauplius II starved for 2 and $4 \mathrm{~d}$ retained the ability to molt, but at a slower overall rate and with increased mortality relative to controls (Lang \& Marcy 1982). All the above information suggests that short-term starvation may be important to the availability of competent larvae in field populations. Starvation may affect larval development either by directly leading to death or by lengthening development time, and thus indirectly increasing the chance of mortality by predation or misrouting to unfavorable environments.

In a previous study, we reared Balanus amphitrite amphitrite nauplii at Skeletonema costatum concentrations of 0 to $10^{6}$ cells $\mathrm{ml}^{-1}$ Cyprids were obtained only at algal concentrations of $10^{4}$ to $10^{6}$ cells $\mathrm{ml}^{-1}$. The cyprids from these different food treatments, however, had similar sizes and metamorphosing capacities (measured as proportions of larvae that eventually metamorphosed) (Qiu \& Qian 1997). Since cyprids in that study were often trapped at the water-air surface by surface tension, it was impossible to quantitatively compare the duration of the cypris stage for individuals obtained from different treatments. In this study, we used sealed Petri dishes, thereby preventing cyprids from having contact with the air-water interface. As a result, the duration of the cypris stage could be quantitatively compared among treatments. There were no significant differences in either the percentage of cyprids metamorphosing or in the duration of the cypris stage among the initial starvation treatments (Fig. 4). These results suggest that feeding history might not influence post-metamorphosis success in $B$. amphitrite amphitrite. In addition, larval size and the amount of reserve contained in a specific larval stage are canalized features evolved in this species (in contrast to some mollusc larvae which reach smaller sizes at competence when starved), therefore allowing the allocation of limited resources to differentiation rather than to growth (Pechenik et al. 1996).

In the sand shrimp Crangon septemspinosa, larval development is food dependent during the first $24 \mathrm{~h}$ after hatching, but much less so in competent larvae (Wehrtmann 1991). A similar phenomenon has been observed in the seastar Asterina miniata (Allison 1994): 10 to $27 \mathrm{~d}$ food deprivation in 1 to $33 \mathrm{~d}$ old larvae led to a significant decrease in survival, while $28 \mathrm{~d}$ food deprivation in 54 to 82 d old larvae did not result in a significantly lower number of survivors. Lang \& Marcy (1982) paid special attention to the starvation resistance of stage II nauplii of Balanus improvisus, presumably because they thought early stages would be the most sensitive to starvation or because nauplius II were easier to obtain. Since larval Balanus amphitrite amphitrite in later stages are progressively larger (Qiu \& Qian 1997) and structurally more complex (Costlow \& Bookhout 1958), their ability to capture food is expected to increase. This study, however, shows that 
MFT increases progressively at each successive larval stage (Fig. 3), suggesting that the later larval stages may be even more vulnerable to short-term starvation, as the presumed increased feeding capacity of later stages does not entirely compensate for increased energy requirements.

The cyprids of Balanus amphitrite amphitrite are often used in bioassays to evaluate the settlement deterrent and attractive qualities of a variety of substances (Rittschof et al. 1984, Holmström et al. 1992. Pechenik et al. 1993, Kon et al. 1995, Willemsen 1995, Bryan et al. 1996, Clare et al. 1996). In these bioassays, the number of larvae settling at given periods of time (usually 24 or $48 \mathrm{~h}$ ) is determined to calculate percent settlement. If metamorphosis is indeed independent of larval feeding history, bioassays using cyprids may proceed even when sublethal starvation is evident in the larval stages

Despile the limitations inherent to laboratory experiments (see Olson \& Olson 1989, Fenaux et al. 1994), this study does indicate that Balanus amphitrite amphitrite larvae can survive short-term food shortages and that starvation can have a detrimental effect on the larvae of this species by lowering survivorship or by lengthening the duration of development.

Acknowledgements. The authors thank M. Wong for statistical consultation, J. Pechenik and 3 anonymous reviewers for comments on the manuscript, J. Zhong for proof reading the manuscript, and L. Soo and S. Chiu for technical support. This study was supported by a Croucher Foundation grant (CF 94/95, SC17) and a RGC grant (HKUST 574/95M) to P.Y.Q.

\section{LITERATURE CITED}

Allison GW (1994) Effects of temporary starvation on larvae of the seastar Asterina miniata. Mar Biol 118:255-261

Anger K (1995) Starvation resistance in larvae of a semiterrestial crab, Sesarma curacaoense (Decapod: Grapsidae). J Exp Mar Biol Ecol 187(2):161-174

Bryan PJ, Rittschof D, McClintock JB (1996) Bioactivity of echinoderm ethanolic body-wall extracts: an assessment of marine bacterial attachment and macroinvertebrate larval settlement. J Exp Mar Biol Ecol 196:79-96

Butman CA, Fréchette M, Geyer WR, Starczak VR (1994) Flume experiments on food supply to the blue mussel Mytilus edulis L. as a function of boundary-layer flow. Limnol Oceanogr 39(7):1755-1768

Clare AS, Eibest LM, Wilbur MM (1996) Effect of tunicamycin on growth and minerization of Balanus amphitrite amphitrite Darwin (Cirripedia). J Crustac Biol 16:285-290

Costlow JD, Bookhout CG (1958) Larval development of BaJanus amphitrite var. denticulata Broch reared in the laboratory. Biol Bull (Woods Hole) 114:284-295

Fenaux L, Strathmann MF, Strathmann RR (1994) Five tests of food-limited growth of larvae in coastal waters by comparison of rates of development and form of echinoplutei. Limnol Oceanogr 39:84-98

Foster BA (1982) Shallow water barnacles from Hong Kong. In: Morton BS, Tseng CK (eds) Proceedings of the first international marine biological. workshop: the marine flora and fauna of Hong Kong and southern China, Hong Kong, 1980. Hong Kong University Press, Hong Kong, p 207-232

Franks PJS (1992) Phytoplankton blooms at fronts: patterns, scales, and physical forcing mechanisms. Aquat Sci 6(3): $121-137$

Gosselin LA, Qian PY (1997) Can bacterivory alone sustain larval development in the polychaete Hydroides elegans and the barnacle Balanus amphitrite? Mar Ecol Prog Ser 161:93-101

Guillard RRL (1975) Culture of phytoplankton for feeding marine invertebrate. In: Smith $\mathrm{WL}$, Chanley $\mathrm{MH}$ (eds) Culture of marine invertebrate animals. Plenum Publishing, New York, p 29-60

Hartnoll RG (1982) Growth. In: Abele LG (ed) The biology of Crustacea, Vol II. Embryology, morphology, and genetics. Academic Press, New York, p 111-196

Holmström C, Rittschof D, Kjelleberg S (1992) Inhibition of settlement by larvae of Balanus amphitrite and Ciona intestinalis by a surface-colonizing bacterium. Appl Environ Microbiol 58:2111-2115

Hudinaga M, Kasahara $\mathrm{H}$ (1941) Larval development of BaJanus amphitrite hawaiensis. Zool Mag (Tokyo) 54:108-118

Kon YK, Miki W, Endo M (1995) L-Tryptophan and related compounds induce larval settlement of the barnacle Balanus amphitrite Darwin. Fish Sci (Tokyo) 61(5):800-803

I.ang WH, Marcy M (1982) Some effects of carly starvation on the survival and development of barnacle nauplii, Balanus improvisus (Darwin). J Exp Mar Biol Ecol 60:63-70

Litaker W, Duke CS, Kenny BE, Ramus J (1993) Short-term environmental variability and phytoplankton abundance in a shallow tidal estuary. II. Spring and fall. Mar Ecol Prog Ser 94:141-154

Mackas D, Denman KL, Abbott MR (1985) Plankton patchiness: biology in the physical vernacular. Bull Mar Sci $37(2): 652-674$

Mary A Sr, Schmidt ARJr, Cannon GW, Hooper IR, Rittschof D (1987) Manual for laboratory fouling studies. Duke University Marine Laboratory, Beaufort, NC

Olson RR, Olson MH (1989) Food limitation of planktotrophic marine invertebrate larvae: does it control recruitment success? Annu Rev Ecol Syst 20:225-247

Pechenik JA (1987) Environmental influence on larval survival and development. In: Giese A, Pearse JS, Pearse VB (eds) Reproduction of marine invertebrates. Vol IX, Chap 8. General aspects: seeking unity in diversity. Blackwell Scientific Publications, Palo Alto, and Boxwood Press, Pacific Grove, CA, p 551-608

Pechenik JA, Hammer K, Weise C (1996) The effect of starvation on acquisition of competence and post-metamorphic performance in the marine prosobranch gastropod Crepidula fornicata (L.). J Exp Mar Biol Ecol 199:137-152

Pechenik JA, Rittschof D, Schmidt AR (1993) Influence of delayed metamorphosis on survival and growth of juvenile barnacle Balanus amphitrite. Mar Biol 115:287-294

Pitcher GC, Walker DR, Mitchell-Innes BA, Moloney CL (1991) Short-term variability during an anchor station study in the southern Benguela upwelling system: phytoplankton dynamics. Prog Oceanogr 28:29-64

Qian PY, Chia FS (1991) Effects of food concentration on larval growth and development of two polychaete worms. Capitella capitata (Fabricius) and Polydora ligni Webster Bull Mar Sci 48:477-484

Qian PY, Chia FS (1993) Larval development as influenced by food limitation in two polychaete worms: Capitella sp. and Polydora ligni. J Exp Mar Biol Ecol 166:93-105

Qiu JW, Qian PY (1997) Effects of food availability, larval 
source and culture method on larval development of $B a l$ anus amphitrite amphitrite Darwin: implications for experimental design. J Exp Mar Biol Ecol 217:47-61

Ren X, Liu R (1978) Studies on Chinese Cirripedia (Crustacea) I. Genus Balanus. Stud Mar Sinica 13:119-196

Rittschof D, Branscomb ES, Costlow JD (1984) Settlement and behavior in relation to flow and surface in larval barnacles, Balanus amphitrite Darwin. J Exp Mar Biol Ecol 82(2-3): 131-146

Staton JL, Sulkin SD (1991) Nutritional requirements and starvation resistance in larvae of the brachyuran crabs Sesarma cinerum (Bosc) and S. reticulatum (Say). J Exp Mar Biol Ecol 152:271-284

Strathmann RR (1987) Larval feeding. In: Giese A, Pearse JS Pearse VB (eds) Reproduction of marine invertebrates. Vol IX, Chap 7. General aspects: seeking unity in diversity. Blackwell Scientific Publications, Palo Alto, and Boxwood Press, Pacific Grove, CA, p 465-550

Strathmann RR, Fenaux L, Strathmann MF (1992) Heterochronic developmental plasticity in larval sea urchins and its implications for evolution of nonfeeding larvae. Evolution $46: 972-986$

Editorial responsibility: Otto Kinne (Editor),

Oldendorf/Luhe, Germany
Tighe-Ford DJ, Power MJD, Vaile DC (1970) Laboratory rearing of barnacle larvae for antifouling research. Helgol Wiss Meersunters 20:393-405

Wehrtmann IS (1991) How important are starvation periods in early larval development for survival of Crangon septemspinosa larvae? Mar Ecol Prog Ser 73:183-190

Willemsen PR (1995) The screening of sponge extracts for antifouling activity using a bioassay with laboratoryreared cyprid larvae of the barnacle Balanus amphitrite. Int Biodeterior Biodegrad 34:361-373

Wu SC, Cai NE (1963) Studies on the life history of Balanus amphitrite communis Darwin. Stud Mar Sinica 4(4): 103-119 (in Chinese with English abstract)

Young CM, Chia FS (1987) Abundance and distribution of pelagic larvae as influenced by predation, behavior, and hydrographic factors. In: Giese A, Pearse JS, Pearse VB (eds) Reproduction of marine invertebrates. Vol IX, Chap 6. General aspects: seeking unity in diversity. Blackwell Scientific Publications, Palo Aito, and Boxwood Press, Pacific Grove, CA, p 385-463

Zar JH (1984) Biostatistical analysis. Prentice Hall, Englewood Cliffs, NJ

Submitted: August 26, 1997; Accepted: November 17, 1997 Proofs received from author(s): December 22, 1997 